\title{
The ecological niche of Dermacentor marginatus in Germany
}

\author{
Melanie Walter $^{1} \cdot$ Katharina Brugger $^{1} \cdot$ Franz Rubel $^{1}$
}

Received: 13 January 2016 / Accepted: 12 February 2016 / Published online: 19 March 2016

(C) The Author(s) 2016. This article is published with open access at Springerlink.com

\begin{abstract}
The ixodid tick Dermacentor marginatus (Sulzer, 1776) is endemic throughout southern Europe in the range of $33-51^{\circ} \mathrm{N}$ latitude. In Germany, however, D. marginatus was exclusively reported in the Rhine valley and adjacent areas. Its northern distribution limit near Giessen is located at the coordinates $8.32^{\circ} \mathrm{E} / 50.65^{\circ} \mathrm{N}$. Particularly with regard to the causative agents of rickettsioses, tularemia, and $\mathrm{Q}$ fever, the observed locations as well as the potential distribution of the vector $D$. marginatus in Germany are of special interest. Applying a dataset of 118 georeferenced tick locations, the ecological niche for $D$. marginatus was calculated. It is described by six climate parameters based on temperature and relative humidity and another six environmental parameters including land cover classes and altitude. The final ecological niche is determined by the frequency distributions of these 12 parameters at the tick locations. Main parameters are the mean annual temperature (frequency distribution characterized by the minimum, median, and maximum of $6.1,9.9$, and $12.2{ }^{\circ} \mathrm{C}$ ), the mean annual relative humidity $(73.7,76.7$, and $80.9 \%)$, as well as the altitude $(87,240,1108 \mathrm{~m})$. The climate and environmental niche is used to estimate the habitat suitability of D. marginatus in Germany by applying the BIOCLIM model. Finally, the potential spatial distribution of D. marginatus was calculated and mapped by determining an optimal threshold value of the suitability index, i.e., the maximum of sensitivity
\end{abstract}

Franz Rubel

Franz.Rubel@vetmeduni.ac.at

1 Institute for Veterinary Public Health, Department for Farm Animals and Veterinary Public Health, University of Veterinary Medicine Vienna, Veterinärplatz 1, 1210 Vienna, Austria and specificity (Youden index). The model performance is expressed by $\mathrm{AUC}=0.91$.

Keywords Tick map · BIOCLIM · Ecological niche . Habitat model $\cdot$ Q fever

\section{Introduction}

In Germany, the ixodid tick Dermacentor marginatus (Sulzer, 1976) was exclusively collected in the Rhine-Main valley, frequently from its main host sheep. Associated with the occurrence and spread of $\mathrm{Q}$ fever (Fig. 1), D. marginatus was recently brought to the focus of public and scientific attention. Because comprehensive studies concerning the occurrence of Dermacentor species in Germany are dated several decades back (Liebisch and Rahman 1976), an updated compilation of georeferenced locations as well as an estimation of the potential distribution of D. marginatus is presented in this study. For the latter, the ecological niche of D. marginatus in Germany was determined, which was also not quantitatively described so far.

D. marginatus, the ornate sheep tick, generally inhabits steppes, Alpine steppes, forest steppes, and semi-desert areas. The species is distributed from northern Africa to central Europe up to Iran, Kazakhstan, and the mountain areas of central Asia. Recently published maps based on georeferenced locations were compiled by Estrada-Peña et al. (2013) and Rubel et al. (2016) depicting D. marginatus locations in the range of $33-51^{\circ} \mathrm{N}$ latitude. An early map showing the geographical distribution was presented by Hohorst (1943). This map coincides well with current maps except the locations in Great Britain. With great certainty, the latter were ticks of the genus Dermacentor reticulatus (Fabricius, 1794), which could not be classified according to modern 


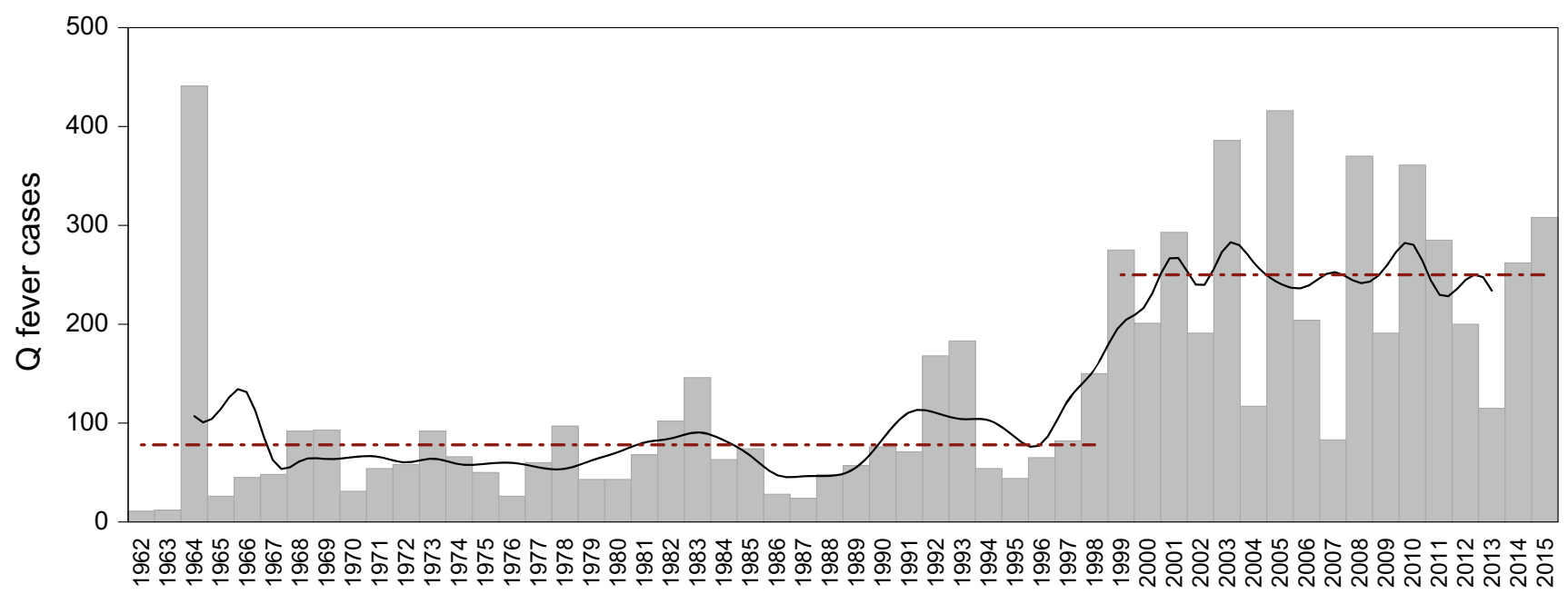

Fig. 1 Q fever cases in Germany after Hellenbrand et al. (2001) and Robert Koch-Institut 2015. Human cases (bars) with 5-year moving average (black line) depict an increase after 1998 by a factor of 3 (dash-dotted lines)

standards at that time (Schulze 1933). Therefore, historical data should be evaluated with special care in relation to the distinction between $D$. marginatus and $D$. reticulatus.

The life cycle of $D$. marginatus includes three blood meals. Adult females engorged in autumn enter diapause and lay their eggs only in the next spring more or less at the same time as those females engorged in early spring. Engorged larvae and nymphs directly develop to the following life stage without a diapause resulting in a complete generation from egg to adult tick within 1 year. Thus, the development from egg to adult tick might take place in a single growing season. In Germany, this may be reached only along the rivers Rhine and Main, where temperatures are high enough for this thermophilic tick (Kahl and Dautel 2008). Adult ticks have a wide host spectrum and occasionally bite humans. It seems that the main hosts for adults in Germany are sheep (Liebisch and Rahman 1976). Other domesticated hosts are dogs, cattle, goats, and horses. As wild animal hosts deer, hare, hedgehog, wolf, and wild boar have been mentioned. Larvae and nymphs feed primarily on small mammals (Petney et al. 2012) but also birds are mentioned hosts (Farkas et al. 2013). Adult ticks are active during spring and early summer as well as in autumn (Nosek 1972). Hornok and Farkas (2009) reported the highest numbers of D. marginatus in February and March, which coincides with the maximum of $D$. marginatus-related disease cases (Oteo and Portillo 2012).

D. marginatus is a potential or proven vector of various zoonotic diseases. In Germany, pathogens detected in $D$. marginatus comprise rickettsiae of the spotted fever group, i.e., Rickettsia slovaca and $R$. raoulti (Řeháček et al. 1977; Pluta et al. 2010) as well as Coxiella burnetii, the causative agent of $Q$ fever (Liebisch et al. 1978). The natural cycle of the $\mathrm{Q}$ fever agent is between $D$. marginatus and rodents. But also larger animals, mainly sheep, were infected and are capable of spreading these bacterial particles to the environment resulting in infections of humans (Sting et al. 2004). Feeding Dermacentor discharge large amounts of feces. The dried feces contain C. burnetii spores and are taken by the wind and spread. This seems to be the main infectious route of $C$. burnetii with Dermacentor involved. In Europe, even more zoonotic pathogens were proven in this tick species. Bonnet et al. (2013) reported D. marginatus ticks infected with Anaplasma phagocytophilum, A. marginale, Bartonella spp., Theileria spp., and Francisella philomiragia in France. The causative agent of equine piroplasmosis, T. equi, was detected in Italy (Iori et al. 2010). D. marginatus is also known to be infected with viral pathogens like the tick-borne encephalitis virus (Hubálek and Rudolf 2012). In Europe, D. marginatus is in focus because of its vector function for $R$. slovaca and $R$. raoulti causing tick-borne-lymphadenopathy, TIBOLA (Parola et al. 2009; Oteo and Portillo 2012). The first human TIBOLA cases in Germany were reported from Freiburg and southern Rhineland-Palatinate (Pluta et al. 2009; Rieg et al. 2011), where D. marginatus as well as $R$. slovaca and $R$. raoulti have been observed (Řeháček et al. 1977; Pluta et al. 2009). As a consequence of the potential expansion of D. marginatus in the course of global warming (Hartelt et al. 2008), TIBOLA may also expand northwards.

Here, parameters derived from climate, land cover, and altitude were used to determine the ecological niche of D. marginatus. To this end, empirical frequency distributions of these parameters at all tick occurrence locations were calculated. Statistical quantities of these frequency distributions were not only used to quantify the environmental envelope of the tick habitats but also to model the potential distribution of $D$. marginatus in Germany. The first model to estimate species distribution was the BIOCLIM algorithm (Busby 1986; Guisan and Zimmermann 
2000), which is applied here. All other models characterizing the climatological niche of species by abiotic factors are based on this method. According to Hijmans and Elith (2015), the large number of algorithms can be divided into three groups: profile methods (e.g., BIOCLIM), regression models and machine learning algorithms. The maximum entropy algorithm MaxEnt (Phillips and Dudík M 2008), which can be assigned to the machine learning models, is the latest developmental stage of these models and presently most often applied to estimate the potential distribution of ticks, for example by Estrada-Peña et al. (2013) and Feria-Arroyo et al. (2014). BIOCLIM, however, was mainly used to estimate the distribution of plant species. One of few BIOCLIM implementations concerning ticks was presented by Jackson et al. (2007) to describe the spread of Ixodes cornuatus and I. holocyclus in southeast Australia. Here, preference is given to BIOCLIM because it guarantees the full understanding and control of the method to the user and, as a by-product, explicitly defines the ecological niche based on environmental parameters. Finally, it is demonstrated that BIOCLIM results in a satisfactory and reliable $D$. marginatus distribution at the regional scale.

\section{Data and methods}

\section{Tick occurrence data}

Georeferenced occurrences of the ixodid tick D. marginatus were taken from the dataset compiled by Rubel et al. (2014). This dataset comprises 77 locations digitized from historical documentations (Liebisch and Rahman 1976) as well as recent observations from Menn (2006). For this study, 41 additional locations (Table 1) were collected resulting in a total of 118 georeferenced $D$. marginatus locations. However, locations described by geographical coordinates determined by GPS in the field were only provided by studies carried out after the turn of the millennium (Menn 2006; Dries 2012; Gilgenast 2013; Kahl 2015). Thus, accuracy measures were given for all data referenced in Table 1. It is distinguished between high (h), medium (m), low (l), and unknown (u) accuracy. A high accuracy $( \pm 0.1 \mathrm{~km})$ was allocated to coordinates given in degrees, minutes, and seconds or in decimal degrees with at least$4-5$ relevant decimal places. A medium accuracy $( \pm 1 \mathrm{~km})$ was assumed for coordinates given in degrees and minutes or in decimal degrees with at least 2-3 relevant decimal places. A medium accuracy was also assumed for ticks collected from animals or humans and for coordinates digitized from local maps $\left(<1000 \mathrm{~km}^{2}\right)$. Coordinates digitized from regional maps $\left(>1000 \mathrm{~km}^{2}\right)$ were classified as low-accuracy data $( \pm 10 \mathrm{~km})$
Table 1 Georeferenced Dermacentor marginatus locations from Germany and the border areas of France, Switzerland and Austria comprising geographical longitude, latitude, accuracy and source. Note that further locations used in this paper have been documented by Rubel et al. (2014)

\begin{tabular}{|c|c|c|c|c|}
\hline No. & Longitude & Latitude & Accuracy & Source \\
\hline 1 & 8.4800 & 49.1336 & $\mathrm{~h}$ & Kahl (2015) \\
\hline 2 & 8.3750 & 49.1353 & $\mathrm{~h}$ & Kahl (2015) \\
\hline 3 & 7.9608 & 48.4442 & $\mathrm{~h}$ & Kahl (2015) \\
\hline 4 & 9.1144 & 48.5850 & $\mathrm{~h}$ & Kahl (2015) \\
\hline 5 & 9.1246 & 49.9785 & $\mathrm{~m}$ & Pluta et al. (2010) \\
\hline 6 & 7.6796 & 47.6187 & $\mathrm{~m}$ & Pluta et al. (2010) \\
\hline 7 & 8.1324 & 49.0529 & $\mathrm{~h}$ & Gilgenast (2013) \\
\hline 8 & 8.0308 & 49.0351 & $\mathrm{~h}$ & Gilgenast (2013) \\
\hline 9 & 7.8933 & 48.4627 & $\mathrm{~h}$ & Dries (2012) \\
\hline 10 & 7.5000 & 48.5000 & $\mathrm{u}$ & Estrada-Peña (2013) \\
\hline 11 & 7.7500 & 48.5833 & $\mathrm{u}$ & Estrada-Peña (2013) \\
\hline 12 & 8.3799 & 49.2164 & $\mathrm{u}$ & Foley et al. (2014) \\
\hline 13 & 11.3720 & 47.2700 & $\mathrm{~m}$ & Thaler (2003) \\
\hline 14 & 10.8590 & 47.2195 & $\mathrm{~m}$ & Thaler (2003) \\
\hline 15 & 10.3818 & 46.8363 & $\mathrm{~m}$ & Thaler (2003) \\
\hline 16 & 11.2722 & 47.2666 & $\mathrm{~m}$ & Thaler (2003) \\
\hline 17 & 7.5539 & 47.6285 & 1 & Immler et al. (1970) \\
\hline 18 & 7.2863 & 47.8130 & 1 & Immler et al. (1970) \\
\hline 19 & 7.4123 & 47.9852 & 1 & Immler et al. (1970) \\
\hline 20 & 7.5680 & 47.6709 & 1 & Sting et al. (2004) \\
\hline 21 & 7.6498 & 47.6710 & 1 & Sting et al. (2004) \\
\hline 22 & 8.4105 & 47.7982 & 1 & Sting et al. (2004) \\
\hline 23 & 7.8218 & 48.0333 & 1 & Sting et al. (2004) \\
\hline 24 & 7.7189 & 48.1334 & 1 & Sting et al. (2004) \\
\hline 25 & 7.7280 & 48.1946 & 1 & Sting et al. (2004) \\
\hline 26 & 8.0096 & 48.4787 & 1 & Sting et al. (2004) \\
\hline 27 & 7.8573 & 48.5147 & 1 & Sting et al. (2004) \\
\hline 28 & 7.8632 & 48.5733 & 1 & Sting et al. (2004) \\
\hline 29 & 8.0351 & 48.6441 & 1 & Sting et al. (2004) \\
\hline 30 & 8.1807 & 48.6636 & 1 & Sting et al. (2004) \\
\hline 31 & 8.2548 & 48.6568 & 1 & Sting et al. (2004) \\
\hline 32 & 8.9929 & 48.4141 & 1 & Sting et al. (2004) \\
\hline 33 & 9.5154 & 48.7082 & 1 & Sting et al. (2004) \\
\hline 34 & 8.6191 & 48.8675 & 1 & Sting et al. (2004) \\
\hline 35 & 8.6278 & 48.9718 & 1 & Sting et al. (2004) \\
\hline 36 & 8.8523 & 48.9577 & 1 & Sting et al. (2004) \\
\hline 37 & 8.5510 & 49.1036 & 1 & Sting et al. (2004) \\
\hline 38 & 8.4922 & 49.1160 & 1 & Sting et al. (2004) \\
\hline 39 & 9.1020 & 49.1084 & 1 & Sting et al. (2004) \\
\hline 40 & 9.1911 & 49.0858 & 1 & Sting et al. (2004) \\
\hline 41 & 9.2612 & 49.0225 & 1 & Sting et al. (2004) \\
\hline
\end{tabular}

Note that Table 1 contains not only tick locations from Germany but also three observations from the Inn river valley in Austria (Thaler 2003) as well as five observations 
from the French and Swiss part of the Rhine river valley (Immler et al. 1970; Estrada-Peña et al. 2013).

\section{Environmental data}

In order to characterize the abiotic habitat of the tick, predictive environmental data comprising climate, land cover, and altitude parameters were used. These gridded data cover the entire region of Germany defined by the rectangular model domain ranging from $5.5^{\circ} \mathrm{E}$ to $15.5^{\circ} \mathrm{E}$ longitude and $47.0^{\circ}$ $\mathrm{N}$ to $55.5^{\circ} \mathrm{N}$ latitude. A grid spacing of $0.1^{\circ}$, corresponding to a cell size of about $80 \mathrm{~km}^{2}$, was selected in accordance to the spatial resolution of the available environmental data. Thus, the model domain is covered by a $85 \cdot 100$ grid.

Climate parameters were derived from temperature and relative humidity data provided by the German Weather Service. Here, the so-called HYRAS dataset from the KLIWAS (Impacts of climate change on waterways and navigation searching for options of adaptation) project is used (Rauthe et al. 2013; Frick et al. 2014). Land cover parameters were taken from the ESA GlobCover 2009 dataset (European Space Agency 2010). It characterizes, specified by satellite images, the land cover based on 22 classes. A total of 16 land cover classes were found in the model domain depicted

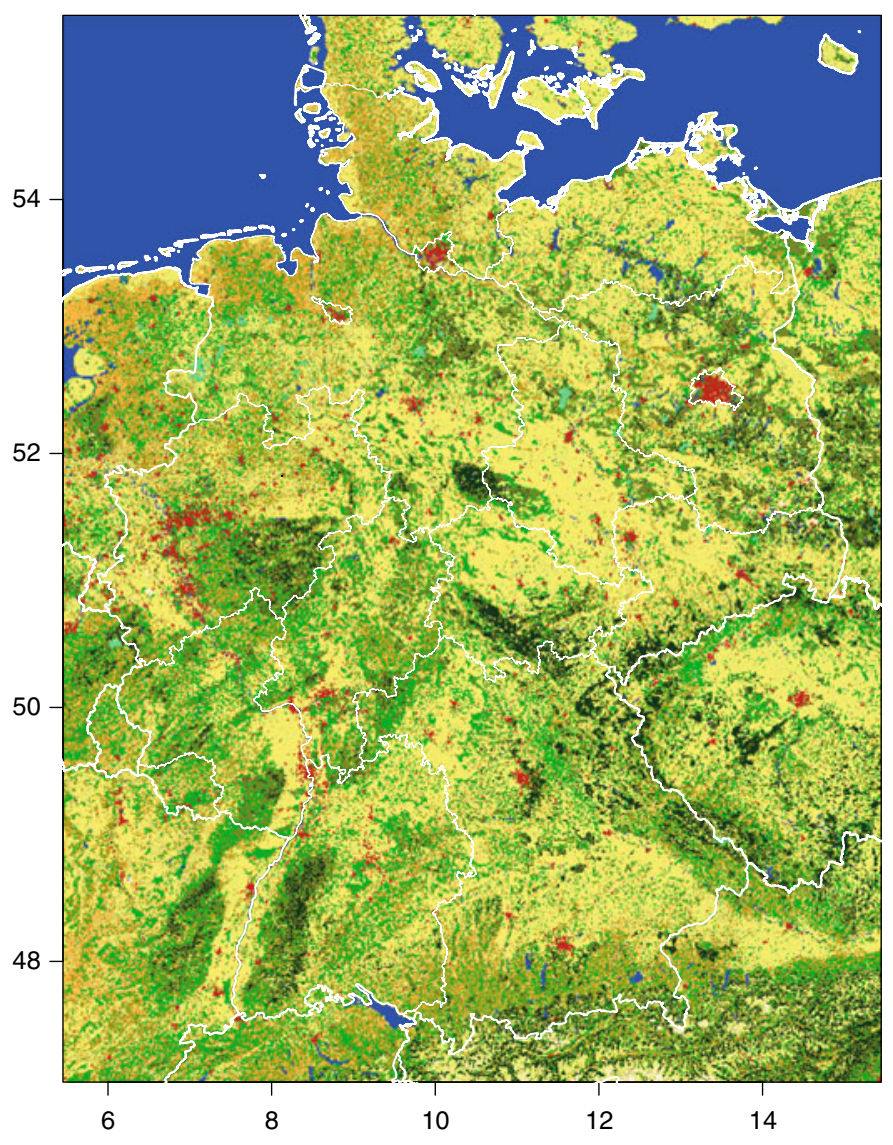

in Fig. 2. The original spatial resolution of these categorical data is $300 \mathrm{~m}$. They were aggregated to the grid spacing of $0.1^{\circ}$ described above by determining the fraction of the land cover classes within each grid cell. By applying this procedure, the categorical land cover classes were converted to continuous data, i.e., fractions of land cover classes within a grid cell. The latter were used as predictive variables in the BIOCLIM model.

\section{BIOCLIM algorithm}

The bioclimatic analysis and prediction system BIOCLIM (Busby 1986, 1991) is used to investigate the ecological niche of D. marginatus in Germany. BIOCLIM may also be characterized as the first and most widely known habitat model or as the classical climate-envelope model. Originally, BIOCLIM creates a climatic profile of the abiotic habitat of a species, the so-called climatic envelope. It is defined by the minimum and maximum of each environmental parameter within the subset of all grid cells where the species was observed, which then form a climatic minimum rectangular envelope in a more-dimensional space (Di Febbraro and Mori 2015). Here, not only climate but also land cover and altitude parameters were used, and

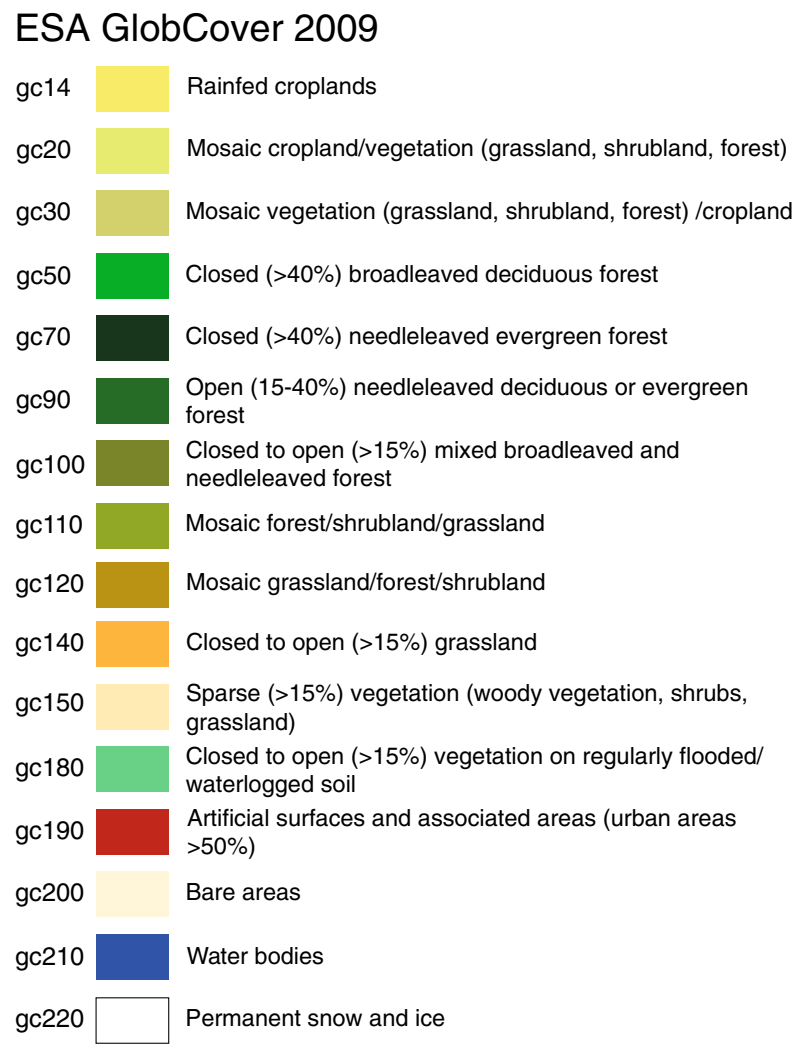

Fig. 2 Model domain with land cover provided by European Space Agency (2010) 
the resulting environmental envelope is assumed to statistically describe the ecological niche. Note that environmental parameters determining the ecological niche should be selected according to the resolved scale. The smaller the scale, the more important are biotic interactions. Relevant parameters on the regional scale considered here are climate, topography, and land use (Pearson and Dawson 2003; Boehnke et al. 2015).

Knowing the ecological niche, i.e., the frequency distributions of the environmental parameters determined from all $D$. marginatus locations, the habitat suitability may be calculated (Hijmans and Graham 2006). For a grid cell and a single parameter, the maximal suitability index of $s i=1$ is calculated for values equal to the median of the frequency distribution. If the parameter value of a grid cell is outside the range defined by the minimum and maximum, the suitability index equals si $=0$. Generally, the suitability index is derived from the percentile rank of a parameter at a specific grid cell. The final suitability index of a grid cell is defined as the lowest suitability index of all environmental parameters (Liebig's law of the minimum). Mapping the suitability indices depicts the potential distribution of a species.

\section{Results}

\section{Ecological niche}

The most common climate classification worldwide (Rubel and Kottek 2011) was developed in the first half of the twentieth century by the German climatologists Wladimir Köppen and Rudolf Geiger, recently updated and projected to climate change scenarios by Kottek et al. (2006) and Rubel and Kottek (2010). According to that KöppenGeiger climate classification, the geographical distribution of D. marginatus (Rubel et al. 2016) is restricted to warm temperate climates which may be fully humid with warm
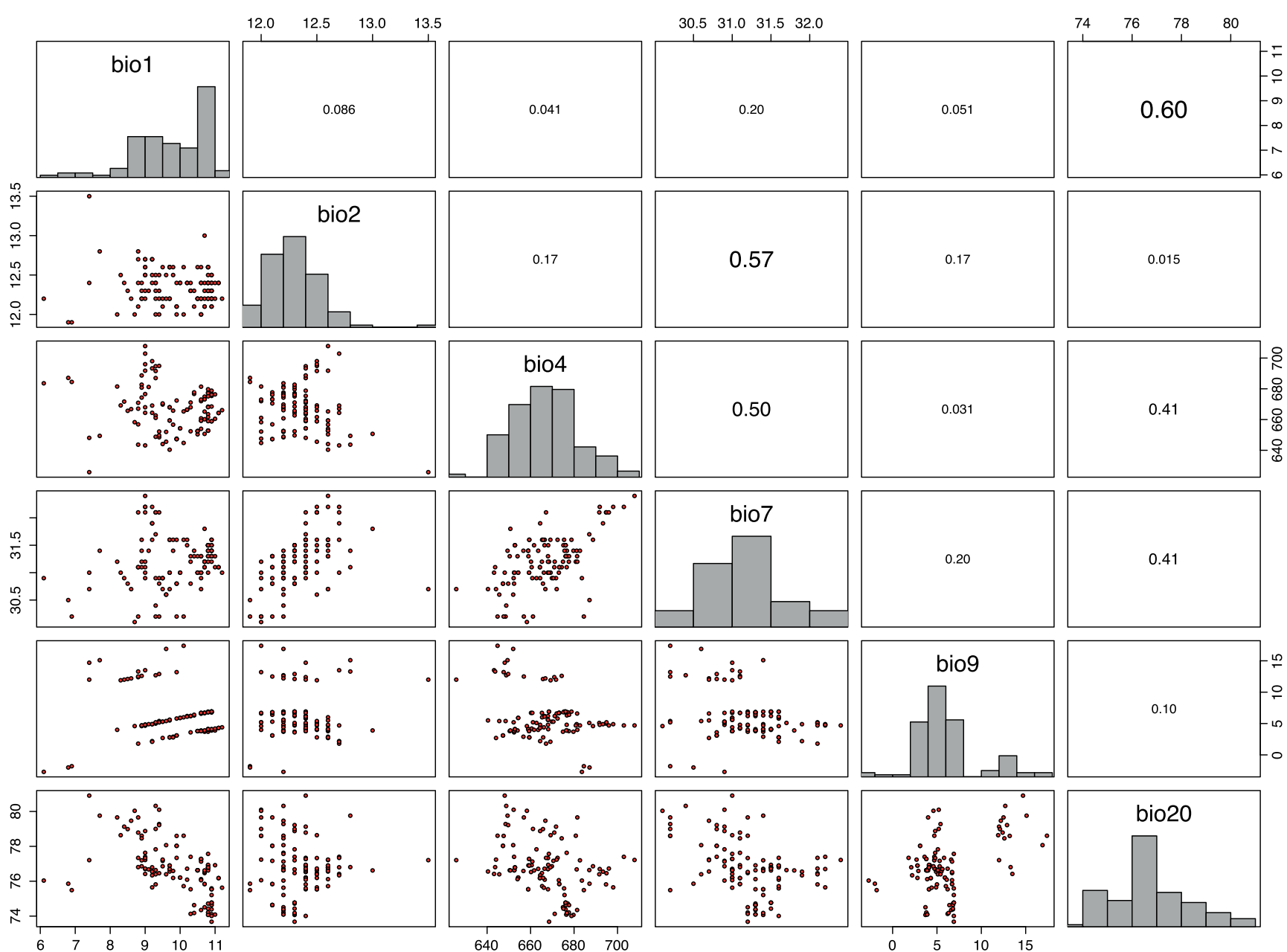

Fig. 3 Selected five bioclimatic parameters of temperature (bio1, bio2, bio4, bio7, bio9) and one bioclimatic variable of relative humidity (bio20). Diagonal: frequency distributions. Lower left: scatter
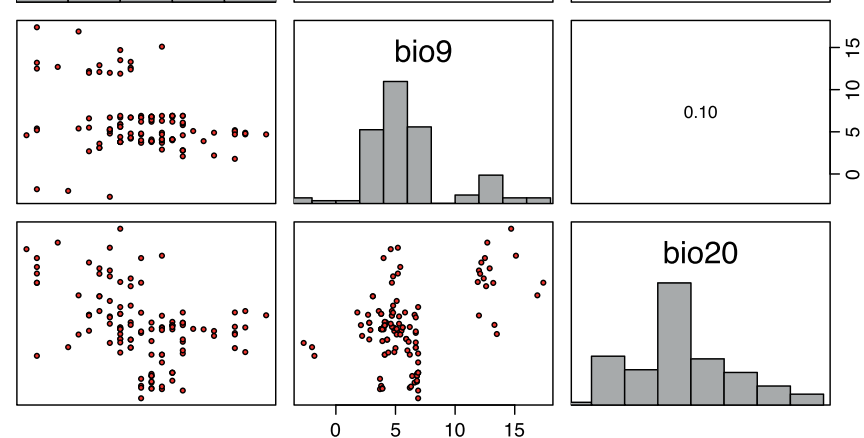

plots. Upper right: Spearman correlation coefficients depicting low collinearity. Parameters correlated above $r_{\mathrm{S}}=0.66$ were removed 
summers(Cfb) or summer dry with warm $(\mathrm{Csb})$ and hot (Csa) summers. The northern distribution limit of $D$. marginatus is located in Germany near Giessen at the coordinates $8.32^{\circ} \mathrm{E} / 50.65^{\circ} \mathrm{N}$. Because almost the entire region of Germany is covered by the $\mathrm{Cfb}$ climate, which is characterized by less hot and dry summers compared to the climate of the main distribution area in the Mediterranean countries, it is necessary to specify the climate and environmental conditions in more detail to capture the observed distribution of $D$. marginatus. Therefore, the 19 well-known bioclimatic parameters (Busby 1986) were calculated from temperature and relative humidity data provided by the German weather service (Frick et al. 2014; Rauthe et al. 2013). Together with the 16 ESA land cover classes (Fig. 2) and the altitude, a total of 36 parameters were investigated to determine the ecological niche of the ticks. Parameters highly correlated with each other were eliminated to reduce the number of parameters as well as to avoid collinearity. Therefore, a threshold Spearman correlation coefficient of $r_{\mathrm{S}}=0.66$ was applied to specify the minimum number of climate parameters necessary for high accuracy habitat modeling (see next section). This threshold was empirically specified from sensitivity analysis (Walter 2015) and is in good agreement with thresholds applied by other authors (Melaun et al. 2015). The correlation analysis results in six bioclimatic parameters (Fig. 3) and six environmental parameters (Fig. 4) selected to define the ecological niche of $D$. marginatus in Germany. In Table 2, these 12 parameters are listed together with the median, the minimum, and the maximum derived from their frequency distributions. The bioclimatic parameter bio1, for example, represents the mean annual temperature characterized by the minimum, median, and maximum of 6.1 , 9.9, and $12.2{ }^{\circ} \mathrm{C}$, bio2 represents the mean diurnal temperature range $\left(11.6,12.3\right.$, and $\left.13.5{ }^{\circ} \mathrm{C}\right)$, etc. Further important parameters comprise the mean annual relative humidity $(73.7,76.7$, and $80.9 \%)$, the fraction of rainfed croplands in a grid cell $(0,0.22,0.75)$, the mosaic cropland/vegetation $(0,0.18,0.55)$ as well as the altitude (87, 240, $1108 \mathrm{~m})$.

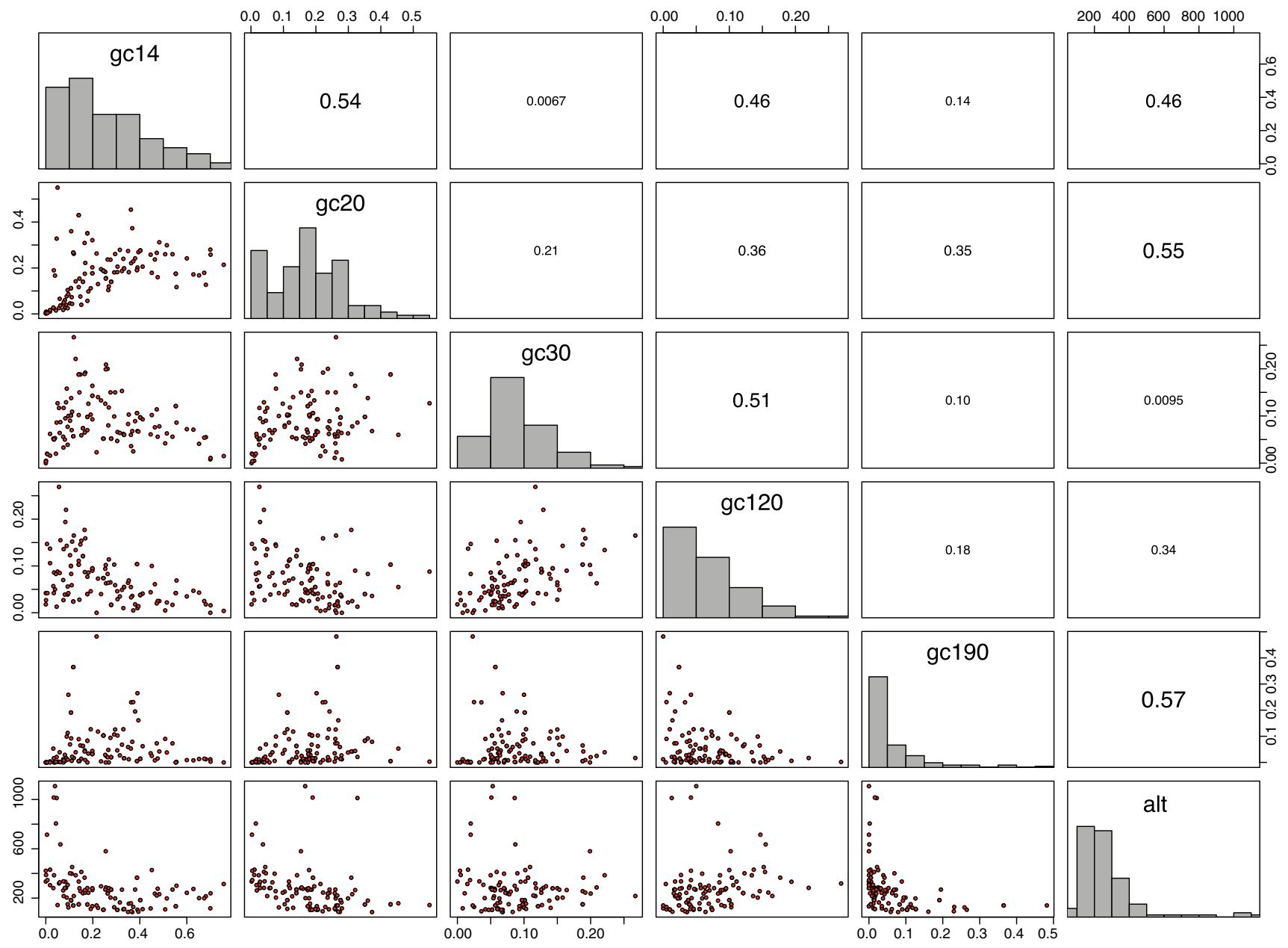

Fig. 4 Selected five landcover classes (gc14, gc20, gc30, gc120, gc190) and altitude (alt). Diagonal: frequency distributions. Lower left: scatter plots. Upper right: Spearman correlation coefficients depicting low collinearity. Parameters correlated above $r_{\mathrm{S}}=0.66$ were removed 
Table 2 Parameters defining the climate and environmental profile by median, minimum and maximum values. Temperatures bio1, bio2, bio4, bio7, and bio9 are given in ${ }^{\circ} \mathrm{C}$, relative humidity bio20 is given in
$\%$, fractions of land classifications in each grid cell gc14, gc20, gc30, gc120, and gc200 are dimensionless and the altitude alt is given in meters above sea level

\begin{tabular}{|c|c|c|c|c|}
\hline Abbr. & Climate and environmental parameters & Min & Median & Max \\
\hline bio1 & Mean annual temperature & 6.1 & 9.9 & 11.2 \\
\hline bio2 & Mean diurnal temperature range & 11.9 & 12.3 & 13.5 \\
\hline bio4 & Temperature seasonality & 6.3 & 6.7 & 7.1 \\
\hline bio7 & Temperature annual range & 30.1 & 31.2 & 32.4 \\
\hline bio9 & Mean temperature of the driest quarter & -2.7 & 5.1 & 17.4 \\
\hline bio20 & Mean annual relative humidity & 73.7 & 76.7 & 80.9 \\
\hline gc14 & Fraction of rainfed croplands & 0 & 0.222 & 0.757 \\
\hline $\operatorname{gc} 20$ & Mosaic cropland/vegetation (grassland, shrub land, forest) & 0.002 & 0.179 & 0.550 \\
\hline gc30 & Mosaic vegetation (grassland, shrub land, forest)/cropland & 0 & 0.077 & 0.267 \\
\hline gc120 & Mosaic forest/shrub land/grassland & 0 & 0.057 & 0.269 \\
\hline gc190 & Artificial surfaces and associated areas (urban areas $>50 \%$ ) & 0 & 0.025 & 0.482 \\
\hline alt & Altitude & 87 & 240 & 1108 \\
\hline
\end{tabular}

\section{Potential species distribution}

For the estimation of the potential species distribution of $D$. marginatus in Germany, the BIOCLIM model was applied together with the 12 parameters (predictive variables) described above. Figure 5a depicts the resulting map of the habitat suitability index (si) overlayed by the observed 118 tick locations (occurrence points). To categorize those regions where the occurrence of $D$. marginatus is most likely, a threshold for the suitability index of si $=0.01$ was determined. From several methods proposed to estimate an optimum threshold, the maximum of sensitivity plus specificity (Youden index) was selected (Liu et al. 2005; Hijmans and Elith 2015). Figure 5b shows the resulting region identified as potential distribution area for D. marginatus. It covers 1508 out of 5770 grid cells (about $27 \%$ ) of the model domain in the southwestern and central part of Germany as well as adjacent regions in France, Switzerland, and the Austrian Inn valley. The modeled $D$. marginatus habitats in Germany not only cover largely the region of known occurrence along the Rhine and Main rivers (Baden-Württemberg, RhinelandPalatinate, Saarland, Hesse, Bavaria) but also extend beyond the east and the north (especially the northern parts of Hesse, North Rhine-Westphalia, Thuringia, Lower Saxony, and Saxony-Anhalt). It is notable that the northernmost populations of D. marginatus were observed at about $51^{\circ} \mathrm{N}$ (near Giessen), while a northern distribution limit of $53^{\circ} \mathrm{N}$ and beyond was modeled (Fig. 5).

The model performance is expressed by the commonly used measure Area Under the Receiver Operated Curve (AUC; Liu et al. 2011; Hijmans and Elith 2015). The calculated value of AUC $=0.91$ is indicative of a good model formation and similar to those of the MaxEnt model for the arbovirus vector Ochlerotatus japonicus japonicus in Germany (Melaun et al. 2015). The latter showed a distribution similar to that of the ixodid tick $D$. marginatus. This is the case at least for the Rhine-Main valley with its warm and dry summers, which is known for the occurrence of various Mediterranean animal and plant species.

\section{Discussion and outlook}

The Rhine-Main valley is located at the northern limit of the current range of the thermophilic tick $D$. marginatus, whose potential distribution was estimated by a habitat model. Thereby, the BIOCLIM model has been preferred over more sophisticated models such as Maxent (Phillips and Dudík M 2008; Schapire 2014) because it is the first and most widely used habitat model; its implementation provides the full access option concerning the model algorithm and not least performs well on the regional scale. In general, the importance of the selected algorithm, i.e., the selected habitat model, decreases with increasing quality of the input data. The latter comprise both the reliability and number of tick occurrence sites as well as the quality of the predictive variables. Comparisons of model algorithms and datasets support this thesis (De Clercq et al. 2015).

Conversely, even the most developed habitat models are not able to predict complete and detailed species distributions if they are based on inadequate data. It is essential that the area of distribution of the target tick has been thoroughly and homogeneously surveyed and that all the possible combinations of climate under which the tick has stable populations are considered (Estrada-Peña et al. 

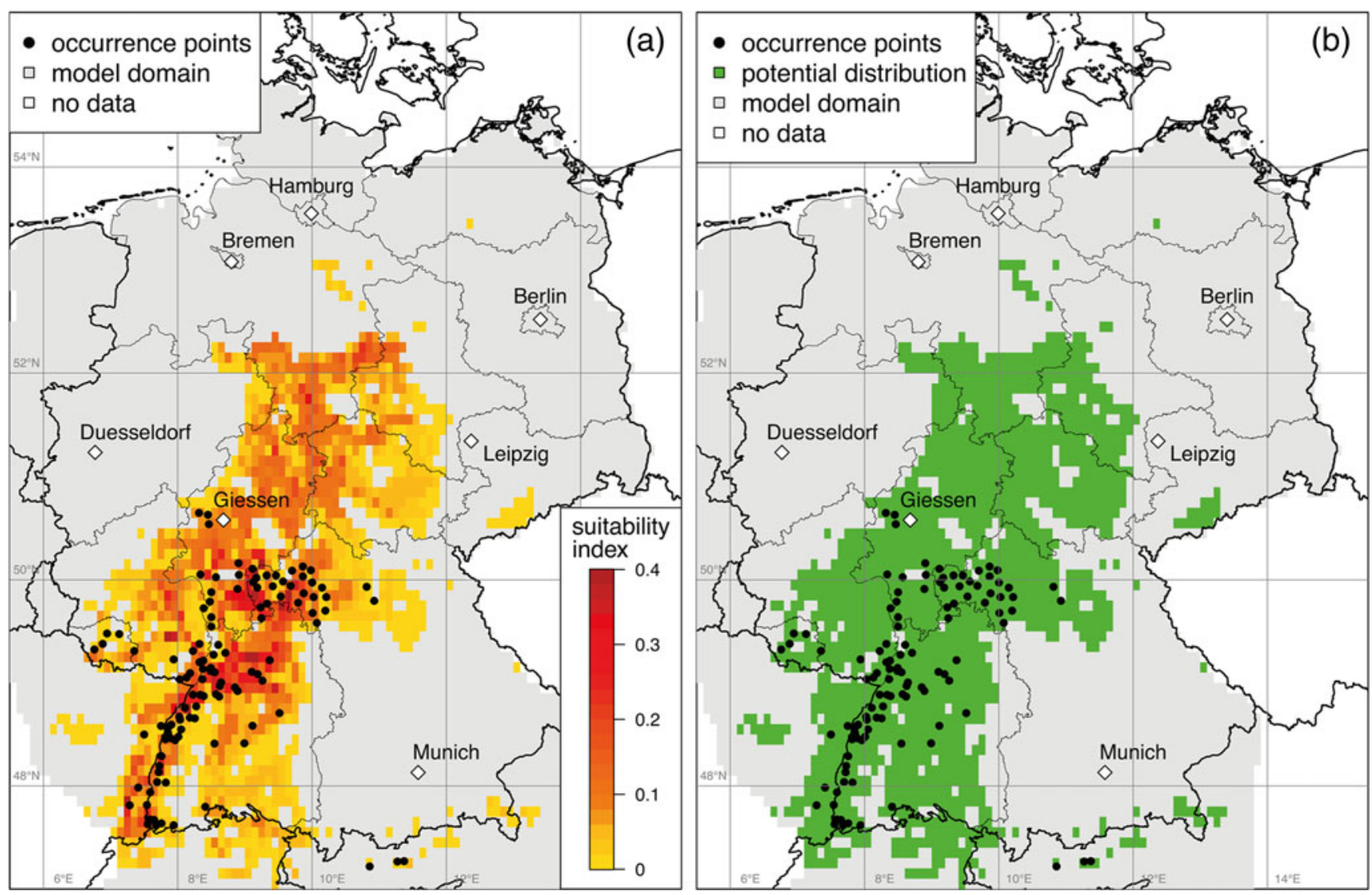

Fig. 5 Distribution of Dermacentor marginatus in Germany. Suitability index (a) and potential distribution (b) with overlayed occurrence points

2014). Otherwise habitat models have serious problems to depict the species distribution in unsampled regions or to project future species distributions based on climate change scenarios. The D. marginatus distribution maps from Williams et al. (2015), estimated with the MaxEnt model, are a good example of this. The model failed to depict the known habitat suitability in Germany (Rubel et al. 2014), Portugal (Santos-Silva et al. 2011), and Romania (Mihalca et al. 2012). As a consequence, also the $D$. marginatus maps projected to climate change scenarios are unrealistic.

In this study, special focus was put on the collection and application of best available data. The $77 \mathrm{D}$. marginatus locations recently collected by Rubel et al. (2014) were complemented by 41 additional locations and the climate parameters (Table 2) were calculated from the national climate database. These regional scale data of the German weather service (Frick et al. 2014; Rauthe et al. 2013) are based on more and more recent ground measurements than the most widely applied climate data provided by Hijmans et al. (2005), which are unrivaled on the global and continental scale. Further, except for the land cover classification, satellite-derived data were not considered. Remotely sensed climate parameters were generally indirectly derived from radiation measurements implying lower accuracy and artefacts (Rubel and Rudolf 2001) or systematic errors (Alonso-Carné et al. 2013), so ground-based measurements were preferred.

A weak point in the available tick observations is that they were mainly collected from sheep, although it is well known that $D$. marginatus may be found on various other hosts, especially on wildlife. Also dogs should be taken into consideration to be hosts for $D$. marginatus as may be deduced from the study by Wächter et al. (2015), who detected antibodies against $R$. raoultii and $R$. slovaca in dogs from the south and southwest of Germany. The results presented should therefore be taken as a basis to perform a new study concerning the species distribution and the vector potential of $D$. marginatus. The latest germanwide study took place more than 40 years ago (Liebisch and Rahman 1976), and the modeled distribution (Fig. 5) provides evidence that $D$. marginatus extended its range northwards and westwards. In these regions, exclusively, D. reticulatus have been described, but a misclassification cannot be excluded.

Acknowledgments Open access funding provided by University of Veterinary Medicine Vienna. The study was supported by the German Federal Environmental Agency, project FKZ 371348 402. We are grateful to Olaf Kahl (tickradar, Berlin, Germany) for reading the final manuscript and providing tick locations. 
Open Access This article is distributed under the terms of the Creative Commons Attribution 4.0 International License (http:// creativecommons.org/licenses/by/4.0/), which permits unrestricted use, distribution, and reproduction in any medium, provided you give appropriate credit to the original author(s) and the source, provide a link to the Creative Commons license, and indicate if changes were made.

\section{References}

Alonso-Carné J, García-Martn A, Estrada-Peña A (2013) Systematic errors in temperature estimates from MODIS data covering the western Palearctic and their impact on a parasite development model. Geospatial Health 8:1-12

Boehnke D, Brugger K, M Pfäffle PS, Norra S, Petney T, Oehme R, Littwin N, Lebl K, Raith J, Walter M, Gebhardt R, Rubel F (2015) Estimating Ixodes ricinus densities on the landscape scale. Int $\mathbf{J}$ Health Geogr 14:23

Bonnet S, de la Fuente J, Nicollet P, Liu X, Madani N, Blanchard B, Maingourd C, Alongi A, Torina A, Fernández de Mera IG, Vicente J, George JC, Vayssier-Taussat M, Joncour G (2013) Prevalence of tick-borne pathogens in adult Dermacentor spp. ticks from nine collection sites in France. Vector Borne Zoonotic Dis 13:226236

Busby J (1986) A biogeoclimatic analysis of Nothofagus cunninghamii (Hook.) Oerst in southeastern Australia. Aust J Ecol 11:1-7

Busby J (1991) BIOCLIM - a bioclimate analysis and prediction system. In: Margules C, Austin M (eds) Nat. Conserv. Cost Eff. Biol. Surv. Data Anal., CSIRO, Melbourne, chap 10, pp 64-68

De Clercq EM, Leta S, Estrada-Peña A, Madder M, Adehan S, Vanwambeke SO (2015) Species distribution modelling for Rhipicephalus microplus (Acari: Ixodidae) in Benin, West Africa: Comparing datasets and modelling algorithms. Prev Vet Med 118:821

Di Febbraro M, Mori E (2015) Potential distribution of alien parakeets in Tuscany (Central Italy): a bioclimatic model approach. Ethol Ecol Evol 27:116-128

Dries R (2012) Study of the tick-density and community structure in the Rhine Plain near Offenburg Bachelor thesis. Karlsruhe Institute of Technology, Germany

Estrada-Peña A (2013) Correlative models, ticks and climate trends: what we want to measure? A candid comment on Porretta et al. (2013)

Estrada-Peña A, Farkas R, Jaenson TGT, Koenen F, Madder M, Pascucci I, Salman M, Tarrés-Call J, Jongejan F (2013) Association of environmental traits with the geographic ranges of ticks (Acari: Ixodidae) of medical and veterinary importance in the western Palearctic. A digital data set. Exp Appl Acarol 59:351-66

Estrada-Peña A, Estrada-Sánchez A, Estrada-Sánchez D (2014) Methodological caveats in the environmental modelling and projections of climate niche for ticks, with examples for Ixodes ricinus (Ixodidae). Vet Parasitol 208:14-25

European Space Agency (2010) GlobCover 2009 (Global Land Cover Map). http://due.esrin.esa.int/page_globcover.php

Farkas R, Estrada-Peña A, Jaenson TGT, Pascucci I, Madder M (2013) Basic biology and geographical distribution of tick species involved pathogens, including zoonoses. In: Salman M, TarrésCall J (eds) Ticks and Tick-borne Diseases, CAB International, pp 6-26

Feria-Arroyo TP, Castro-Arellano I, Gordillo-Perez G, Cavazos AL, Vargas-Sandoval M, Grover A, Torres J, Medina RF, de León AaP (2014) Esteve-Gassent MD Implications of climate change on the distribution of the tick vector Ixodes scapularis and risk for
Lyme disease in the Texas-Mexico transboundary region. Parasit Vectors, vol 7, p 199

Foley D, Rueda P, Wilkerson R (2014) VectorMap of the Walter Reed Biosystematics Unit (WRBU), Smithsonian Institution, Washington DC. Tick maps available at http://www.tickmap.org/

Frick C, Steiner H, Mazurkiewicz A, Riediger U, Rauthe M, Reich T, Gratzki A (2014) Central European high-resolution gridded daily data sets (HYRAS): mean temperature and relative humidity. Meteorol Z 23:15-32

Gilgenast M (2013) Vergleich der Abundanz von D. marginatus auf Schafen am Bienwald (Südpfalz) in den Jahren 2011-2013. Zulassungsarbeit, Karlsruhe Institute of Technology, Germany

Guisan A, Zimmermann NE (2000) Predictive habitat distribution models in ecology. Ecol Modell 135:147-186

Hartelt K, Pluta S, Oehme R, Kimmig P (2008) Spread of ticks and tick-borne diseases in Germany due to global warming. Parasitol Res 103(Suppl 1):S109-S116

Hellenbrand W, Breuer T, Petersen L (2001) Changing epidemiology of Q fever in Germany, 1947-1999. Emerg Inf Dis 7:789-796

Hijmans RJ, Elith J (2015) Species distribution modeling with R. http://cran.r-project.org/web/packages/dismo/vignettes/sdm.pdf

Hijmans RJ, Graham CH (2006) The ability of climate envelope models to predict the effect of climate change on species distributions. Glob Chang Biol 12:2272-2281

Hijmans RJ, Cameron SE, Parra JL, Jones PG, Jarvis A (2005) Very high resolution interpolated climate surfaces for global land areas. Int J Climatol 25:1965-1978

Hohorst W (1943) Die Zecke Dermacentor marginatus Sulzer 1776, ihre Verbreitung, Lebensweise und Medizinische Bedeutung. Z Parasitenkd 13:118-146

Hornok S, Farkas R (2009) Influence of biotope on the distribution and peak activity of questing ixodid ticks in Hungary. Med Vet Entomol 23:41-6

Hubálek Z, Rudolf I (2012) Tick-borne viruses in Europe. Parasitol Res 111:9-36

Immler R, Aeschlimann A, Büttiker W, Diehl P, Eichenberger G, Weiss N (1970) Über das Vorkommen von Dermacentor-Zecken (Ixodoidea) in der Schweiz. Bull Soc Entomol Suisse 43:99-110

Iori A, Gabrielli S, Calderini P, Moretti A, Pietrobelli M, Tampieri MP, Galuppi R, Cancrini G (2010) Tick reservoirs for piroplasms in central and northern Italy. Vet Parasitol 170:291-296

Jackson J, Beveridge I, Chilton NB, Andrews RH (2007) Distributions of the paralysis ticks Ixodes cornuatus and Ixodes holocyclus in south-eastern Australia. Aust Vet J 85:420-4

Kahl O (2015) Personal communication

Kahl O, Dautel H (2008) Zur Biologie und Ökologie von Zecken und ihre Ausbreitung nach Norden. In: Lozán JL (ed) Warnsignal Klima: Gesundheitsrisiken - Gefahren für Pflanzen. Universität Hamburg, Tiere Menschen, pp 215-218

Kottek M, Grieser J, Beck C, Rudolf B, Rubel F (2006) World map of the Köppen-geiger climate classification updated. Meteorol Z 15:259-263

Liebisch A, Rahman MS (1976) Prevalence of the ticks Dermacentor marginatus (Sulzer, 1776) and Dermacentor reticulatus (Fabricius, 1794) and their importance as vectors of diseases in Germany (in German). Tropenmed Parasitol 27:393-404

Liebisch A, Burgdorfer W, Rahman MS (1978) Epidemiological investigations into the prevalence of rickettsiae in sheep ticks (Dermacentor marginatus) (in German). Dtsch Tierärztl Wschr 85:121126

Liu C, Berry PM, Dawson TP, Pearson RG (2005) Selecting thresholds of occurrence in the prediction of species distributions. Ecography 3:385-393

Liu C, White M, Newell G (2011) Measuring and comparing the accuracy of species distribution models with presence-absence data. Ecography 34:232-243 
Melaun C, Werblow A, Cunze S, Zotzmann S, Koch LK, Mehlhorn H, Dörge DD, Huber K, Tackenberg O, Klimpel S (2015) Modeling of the putative distribution of the arbovirus vector Ochlerotatus japonicus japonicus (Diptera: Culicidae) in Germany. Parasitol Res 114:1051-61

Menn B (2006) Untersuchungen zur Verbreitung und Ökologie von Dermacentor Spec. (Ixodidae, Acari) in Deutschland Diploma thesis, University of Bonn, Germany

Mihalca AD, Dumitrache MO, Magdas C, Gherman CM, Domsa C, Mircean V, Ghira IV, Pocora V, Ionescu DT, Barabási SS, Cozma V, Sándor AD (2012) Synopsis of the hard ticks (Acari: Ixodidae) of Romania with update on host associations and geographical distribution. Exp Appl Acarol 58:183-206

Nosek J (1972) The ecology and public health importance of Dermacentor marginatus and D. reticulatus ticks in Central Europe. Folia Parasitol (Praha) 19:93-102

Oteo JA, Portillo A (2012) Tick-borne rickettsioses in Europe. Ticks Tick Borne Dis 3:271-8

Parola P, Rovery C, Rolain JM, Brouqui P, Davoust B, Raoult D (2009) Rickettsia slovaca and $\mathrm{R}$. raoultii in tick-borne Rickettsioses. Emerg Infect Dis 15:1105-1108

Pearson RG, Dawson TP (2003) Predicting the impacts of climate change on the distribution of species: are bioclimate envelope models useful? Glob Ecol Biogeogr 12:361-371

Petney TN, Pfäffle MP, Skuballa JD (2012) An annotated checklist of the ticks (Acari: Ixodida) of Germany. Syst Appl Acarol 17:115170

Phillips SJ, Dudík M (2008) Modeling of species distributions with Maxent: new extensions and a comprehensive evaluation. Ecography 31:161-175

Pluta S, Tewald F, Hartelt K, Oehme R, Kimmig P, Mackenstedt U (2009) Rickettsia slovaca in Dermacentor marginatus ticks, Germany. Emerg Infect Dis 15:2077-2078

Pluta S, Hartelt K, Oehme R, Mackenstedt U, Kimmig P (2010) Prevalence of Coxiella burnetii and Rickettsia spp. in ticks and rodents in southern Germany. Ticks Tick Borne Dis 1:145-147

Rauthe M, Steiner H, Riediger U, Mazurkiewicz A, Gratzki A (2013) A Central European precipitation climatology. Part I: Generation and validation of a high-resolution gridded daily data set (HYRAS). Meteorol Z 22:235-256

Řeháček J, Liebisch A, Urvölgyi J, Kováčová E (1977) Rickettsiae of the spotted fever group isolated from Dermacentor marginatus ticks in south Germany. Zentralbl Bakteriol Mikrobiol Hyg [A] 239:275-281

Rieg S, Schmoldt S, Theilacker C, de With K, Wölfel S, Kern WV, Dobler G (2011) Tick-borne lymphadenopathy (TIBOLA) acquired in southwestern Germany. BMC Infect Dis 11:167
Robert Koch-Institut (2015) Infektionsepidemiologisches Jahrbuch meldepflichtiger Krankheiten für 2014, Berlin:232

Rubel F, Kottek M (2010) Observed and projected climate shifts 1901-2100 depicted by world maps of the Köppen-Geiger climate classification. Meteorol Z 19:135-141

Rubel F, Kottek M (2011) Comments on: 'The thermal zones of the Earth' by Wladimir Köppen (1884). Meteorol Z 20:361365

Rubel F, Rudolf B (2001) Global daily precipitation estimates proved over the European Alps. Meteorol Z 10:407-418

Rubel F, Brugger K, Monazahian M, Habedank B, Dautel H, Leverenz S, Kahl O (2014) The first German map of georeferenced ixodid tick locations. Parasit Vectors 7:477

Rubel F, Brugger K, Pfeffer M, Chitimia-Dobler L, Didyk YM, Leverenz S, Dautel H, Kahl O (2016) Geographical distribution of Dermacentor marginatus and Dermacentor reticulatus in Europe. Ticks Tick Borne Dis 7:224-233

Santos-Silva MM, Beati L, Santos AS, Sousa RD, Nuncio MS, Melo P, Santos-Reis M, Fonseca C, Formosinho P, Vilela C, Bacellar F (2011) The hard-tick fauna of mainland Portugal (Acari: Ixodidae): an update on geographical distribution and known asso ciations with hosts and pathogens. Exp Appl Acarol 55: $85-121$

Schapire RE (2014) Maxent software for species habitat modelling. https://www.cs.princeton.edu/schapire/maxent/

Schulze P (1933) Die Arten der Zeckengattung Dermacentor s. 1. aus Europa, Asien und Neu-Guinea. Z Parasitenkd 6:416-431

Sting R, Breitling N, Oehme R, Kimmig P (2004) Studies on the prevalence of Coxiella burnetii in sheep and ticks of the genus Dermacentor in Baden-Wuerttemberg (in German). Dtsch tierärztl Wochenschr 111:390-394

Thaler K (2003) Fragmenta Faunistica Tirolensia - XV (Arachnida: Araneae, Acari [Ixodida]; Diplopoda; Insecta: Archaeognatha, Zygentoma, Blattariae). Ber nat-med Verein Innsbruck 90:151163

Wächter M, Wölfel S, Pfeffer M, Dobler G, Kohn B, Moritz A, Pachnicke S, Silaghi C (2015) Serological differentiation of antibodies against Rickettsia helvetica, R. raoultii, R. slovaca, R. monacensis and R. felis in dogs from Germany by a microimmunofluorescent antibody test. Parasit Vectors 8:126

Walter M (2015) A climatological habitat model for the distribution of the disease vector Dermacentor marginatus in Germany, Master thesis, Johannes Gutenberg University Mainz

Williams HW, Cross DE, Crump HL, Drost CJ, Thomas CJ (2015) Climate suitability for European ticks: assessing species distribution models against null models and projection under AR5 climate. Parasit Vectors 8:440 